Enrique Ferrari Nieto

Universidad de Valladolid

\title{
EL 98 QUE PLANTEA ORTEGA: BISAGRA DE SENSIBILIDADES EN EL TANTEO DE GENERACIONES
}

Palabras clave: razón vital, sensibilidad vital, generación, noventayochistas, sensibilidad negativa, Andrés Hurtado

En sus reflexiones estéticas sabemos que Ortega no suele ceñir el recorrido de su propuesta a los límites de lo estrictamente artístico, sino que encaja su pensamiento estético, que articula primero con lo formal, en un entramado de enlaces con el que intenta dar con una respuesta global a su tiempo. Con lo que lo estético, sin perder su autonomía, inicia una reflexión más ambiciosa que alimenta, a su vez, una nueva perspectiva sobre el objeto estético, que permite otras lecturas menos obvias desde cada uno de los enlaces con los que lo piensa Ortega. De este modo, con el 98, las referencias a los escritores con un enfoque de conjunto, de grupo literario, trascienden, desde la noción -básica en su filosofía- de generación, las cuestiones meramente literarias, en las que apenas se detiene, para tomar una nueva orientación, como precursores de una época nueva, dentro de un planteamiento más abarcador de sensibilidades vitales: como un paso más, el penúltimo, que cierra sensibilidades pasadas, la inmediata, la de la Restauración, y también el fondo del Idealismo, y abre una nueva sensibilidad, con ese movimiento de negación, para un tiempo en el que la juventud y el deporte imponen sus formas. Porque su época es un tiempo de crisis. Husserl había hablado ya de una crisis de las ciencias europeas: una crisis que, más allá de unos resultados o unos métodos, se apodera -según Ortega- de la vida en su totalidad y, con ello, contribuye a una crisis vital, a una crisis de la humanidad como proyecto racional. Es, dice, un tiempo de inautenticidad, de vida equívoca, en el que el hombre se siente perdido, desorientado respecto a sí mismo.

La postura moderna ha agotado sus posibilidades, y es necesario, dice, otro gran viraje, que quiere engordar con su propuesta, que nace con la mentalidad de este tiempo nuevo, que ha dejado atrás, o lo está haciendo, el respeto excesivo a la razón, degenerado, en muchos casos, en beatería. Él busca un equilibrio. No rechaza la razón, pero la baja del trono y la pone al servicio de la vida. Porque no puede sustituirla, o desvincularse de ella. Ortega dilata su sentido, para que sea de verdad respuesta a la vida de cada hombre. Esa razón pura debe dar paso, dice, a la razón vital: Una razón que es herramienta para la vida, que surge tras asumir la circunstancia como un elemento más de un «yo» más rico que el idealista, en el que coexisten los dos elementos, como los Dii consentes. Una razón que reconoce que las últimas cosas solo se conocen por sí mismas, de manera intuitiva, irracional. Que el intelecto no saca de dentro de sí los conceptos fundamentales, sino que le vienen impuestos por la circunstancia, por las necesidades vitales. Porque el pensamiento, lejos de ser una realidad única y primaria, es consecuencia del existir. Lo que existe no es la conciencia, sino un hombre con un 
contorno de cosas que interpreta y valora desde una cierta altitud vital que le da su generación.

Generación (el compromiso dinámico entre masa e individuo) es, en Ortega, el concepto más importante en la comprensión de la historia, porque es el gozne o la bisagra sobre el que ejecuta sus movimientos (III, 147) ${ }^{1}$. Cada una con una arquitectura propia para el drama que es siempre la vida humana (IX, 517). Porque cada generación reduce el mundo a un horizonte propio y a él se subordina todo: como una cierta altitud vital desde la cual se siente la existencia de una manera determinada (III, 148). Con unos supuestos determinados, que son más o menos distintos a los de otras, porque el sistema de verdades, de valores estéticos, políticos, morales o religiosos, tiene una dimensión histórica. Cada una tiene una peculiar sensibilidad, un modo diferente de pensar y de sentir, que representa con una imagen que repite varias veces: la de una caravana en la que va un hombre, prisionero y a la vez satisfecho, fiel, dice, a los poetas de su edad, a las ideas políticas de su tiempo, al tipo de mujer triunfante en su mocedad y hasta al modo de andar usado a los veinticinco años. De vez en cuando ve pasar otra caravana con su raro perfil extranjero: es la otra generación, que en un día festival, escribe, la orgía mezcla, pero a la hora de vivir la existencia normal, la caótica fusión se disgrega en los dos grupos verdaderamente orgánicos, con los que cada individuo reconoce su propia colectividad (IV, 92). Todos los que viven en un momento determinado bajo una misma atmósfera son contemporáneos, pero solo son coetáneos -y, por tanto, forman una generación- aquellos que tienen la misma edad y algún contacto vital (V, 38): solo los que dan al mismo tiempo el paso para que camine la historia.

Establece una cronología muy precisa (nada que ver con la de la sociología positivista del XIX): cada generación actúa alrededor de treinta años en dos etapas diferentes. En la primera mitad de ese periodo, la nueva generación hace propaganda de sus ideas, de sus gustos; se va abriendo camino para desplazar a la generación anterior de su puesto privilegiado. Son quince años de esfuerzo para alcanzar la cima. Los quince años restantes son los de su dominio. Sus ideas son aceptadas. Pero también debe resistir el empuje de una nueva generación que quiere imponer sus nuevas ideas. «Cada generación -escribe en 'Misión de la Universidad', en 1930- lucha quince años para vencer y tiene vigencia sus modos otros quince años» (IV, 317). Porque en cada presente coexisten tres generaciones: la de los jóvenes, la de los hombres maduros y la de los viejos. Que, al ser diferentes, viven en esencial hostilidad (IV, 91). Y ese enfrentamiento -elemento clave en el concepto de generación de Ortega que lo diferencia, según dice, de las ideas insinuadas por Lorenz, Harnack y Dilthey (IV, 91n.)- es lo que impide el estancamiento de la historia. Porque el antagonismo entre las edades que comparten un tiempo histórico hace que la historia, en vez de mantener una posición o dirección constante, dé virajes imprevistos o abandone proyectos anteriores que ya no interesan a la nueva generación. Porque generación no es genealogía, la serie biológica (o, mejor, zoológica) de hijos, padres y abuelos $(\mathrm{V}, 44)$. Las generaciones no son una sucesión, sino polémica. Y esa polémica es la que

Como ha quedado establecido en los estudios orteguianos, el número en romano hace referencia al tomo y los arábigos a la página de las Obras completas de José Ortega y Gasset editadas en Alianza Editorial en 1983. 
inyecta ese dinamismo a la historia: «Lo decisivo en la idea de las generaciones no es que se suceden, sino que se solapan o empalman. Siempre hay dos generaciones actuando al mismo tiempo, con plenitud de actuación, sobre los mismos temas y en torno a las mismas cosas -pero con distinto índice de edad y, por ello, con distinto sentido» (V, 49). El joven, dice, no aprende del viejo, como se ha escrito en los antiguos libros retóricos, sino que se enoja y aburre con el anciano, y hace lo contrario de lo que éste le sugiere: Lo que queda de fondo en el enfrentamiento de Andrés Hurtado con su padre, por ejemplo, al comienzo de El árbol de la ciencia, con el que Baroja decide el perfil de un protagonista que se siente solo y abandonado para representar al nuevo hombre del 98. Con lo que cada nueva generación da un nuevo viraje que impide que se cumplan los proyectos de la anterior (IV, 18). Aunque para cada una vivir es una faena de dos dimensiones: una, recibir lo vivido por la anterior y, la otra, dejar fluir su propia espontaneidad. Si no establece grandes diferencias entre lo recibido y lo propio da lugar a épocas cumulativas; en cambio, cuando siente una profunda heterogeneidad entre ambos elementos sobreviene una época eliminatoria y polémica, en la que los jóvenes, en lugar de conservar lo heredado, lo sustituyen, y comienza una edad de iniciación y beligerancia constructiva (III, 149). Será estéril una generación cuando no sea capaz de abandonar las ideas recibidas para afirmar sus propios principios. Porque ante todo ha de ser fiel a sí misma, porque cada una tiene su vocación propia, una misión determinada, un deber adscrito a su vida: «Cada generación no es, a la postre, sino eso: una determinada misión, ciertas precisas cosas que hay que hacer» (VIII, 42), escribe. Lo que los hebreos, recuerda, llaman Neftali: «Yo he combatido mis combates» (III, 163).

Las generaciones que faltan a su vocación, que no cumplen su misión, dice, son infieles a sí mismas. La suya, por ejemplo (VII, 293): porque en El tema de nuestro tiempo denuncia que pocas veces en la historia los hombres han vivido menos en claro consigo mismos y han soportado con esa docilidad formas que no le son afines; de ahí esa apatía en política o en arte (III, 151). Diez años después, con En torno a Galileo, le pone a la última generación un principio y un fin, desde 1917 a 1932: con unos pocos rasgos: las nuevas formas políticas, el fascismo y el bolchevismo, y el cubismo pictórico y una poesía semejante (V, 54). La que, con el cálculo de los quince años, es también su generación (no solo en España, sino en Europa): la que, con el nombre que empleó por primera vez Lorenzo Luzuriaga en 1947, han llamado del 14 (Molinuevo, 2002: 24), en los años de su dominio, que marcó, con su magisterio persuasivo, a las generaciones posteriores: en filosofía y, también, con un nuevo prisma para el conocimiento, en la literatura y el arte de vanguardias (Rodríguez Huéscar, 1994: 191). Con lo que deja, para la anterior, mientras él y sus coetáneos (con Meditaciones del Quijote, en 1914, por ejemplo) van abriéndose paso, la franja más o menos nítida entre 1902 y 1917: que, con Camino de perfección o La voluntad ese mismo año, domina en la literatura española la Generación del 98, con el término consensuado para agrupar a aquellos escritores que comenzaron a publicar en la última década del XIX, aunque sea sólo, como escribió Abellán, un cruce de biografías (Abellán, 1995: 21): con el nombre que dio Azorín en 1913 con una nómina más precisa que la de Ortega (cohesionada en las tertulias, periódicos y editoriales de Madrid), una vez pasado su momento (Mainer, 1986: 132), en la que resalta el efecto del desastre 
colonial, pero también las filosofías de Schopenhauer y Nietzsche, las literaturas rusa y francesa, y la ideología anarquista.

En los libros de Ortega las referencias al 98 apenas son unas pocas notas -un análisis muy sobrio en «Pío Baroja: anatomía de un alma dispersa»- como grupo heterogéneo de escritores (del que ya no se considera parte) que empezaron a publicar en 1898, representados en el Andrés Hurtado de Baroja (IX, 491). Con una lista que no es exhaustiva: Unamuno, Benavente, Valle-Inclán, Maeztu, Azorín, Baroja ... Como fruto de una nueva sensibilidad emergente: una sensibilidad negativa (la negación como sensibilidad), que es una barbarie redentora. Porque apenas comparten algo positivo. Sólo su rechazo a la España pretérita, a la mitología peninsular: el casticismo y la tradición nacional, los valores adquiridos a los que estos oponen su modernidad. Convergen sólo en su certeza de la incapacitación de la España constituida, la España ornamental y sin sustancia que era sólo un ademán. Y, por ello, en la necesidad de crear una España desde los cimientos, a nihilo (IX, 494-496). Los hombres del 98 se encontraron sin una nación en que realizarse ni individualidades a quienes seguir. Escribe: «Los hombres de la generación de Baroja que han valido algo tienen, en diferentes grados, el rasgo común de parecer gentes a quienes un incendio acaba de arrojar de su casa y andan despavoridos buscando otro albergue, sin que el azoramiento alojado en ellos les permita descubrirlo ni aun topar con los caminos reales que a poblado conducen. Y van a campo traviesa soliviantados y quien no los conozca habrá de tomarlos por malhechores intelectuales» (IX, 497). Fue, por tanto, una generación fantasma. Sólo pudieron vivir teóricamente, críticamente, para hacerse sitio en un mercado que dominaban los viejos (Calvo, 1998: 13). Pero su análisis -les reconoce Ortega, que estudia, en este aspecto, sobre todo a Baroja y a Azorín- es un primer paso en la posibilidad de una vida nueva (X, 226-227). Y, por ello, se siente de algún modo sucesor de ellos. Incluso fue el primero en dar nombres para el 98, con un alcance más amplio, en el que al principio se incluía también él mismo, muy amigo, por ejemplo, de Maeztu esos primeros años. Pero pronto se distancia: sobre todo como intelectual, frente a la figura del juglar, del que se exhibe a sí mismo porque le faltan las ideas, que ve representado en Unamuno, primero un referente y luego un anti-paradigma (Marichal, 1990: 36), y también en Ganivet o Shaw. Aunque mantiene el reconocimiento de la deuda de su propia generación. Como si los noventayochistas fueran la bisagra que cierra y abre dos sensibilidades casi antagónicas, porque rechazan la anterior, la de la Restauración, que intentan borrar (Mainer, 1986: 20-21), pero no dan el paso positivo de afirmarse en una nueva sensibilidad, o sentimentalidad, como prefiere Juan de Mairena (Machado, 1984: 58): la sensibilidad del tiempo de Ortega: la que sigue a esa Restauración que él detesta: un periodo nuevo, que se delata en dos rasgos que son opuestos a los de los restauradores: «la de abrigar vivas sospechas sobre el positivo vigor histórico de nuestra raza y, en consecuencia, la de estar dispuestos a anteponer todos aquellos medios que sean necesarios para avivarlas a las meras ficciones y apariencias de buen gobierno» (I, 279).

Se quedan en ese primer movimiento del mecanismo con su negación: con su reclamación de autenticidad frente a la falsificación del periodo anterior, que personaliza en Juan Valera: como un «Dios-Pan sonriente y ciego que perdura en el yermo jardín de nuestras bellas letras como la estatua blanca y rota de una deidad gentílica» (I, 26): el Va- 
lera crítico, no el escritor, de completa insensibilidad de las diferencias (I, 160), con una crítica del rebajamiento, fruto de un positivismo inconsciente, propio de la raza, escribe en 1910, en «La crítica de Valera. -De la dignidad del hombre.- Valera como celtíbero» (I, 161): La Restauración, con el régimen político que se instauró en España en 1874 con el restablecimiento de la monarquía borbónica con Alfonso XII, y que terminó en 1902, con la mayoría de edad de Alfonso XIII, a la que Ortega le reprocha el retraso de España respecto a Europa, la pobre herencia que han recibido ellos (I, 284), por este periodo de paralización de la vida española, de un panorama de fantasmas en el que Cánovas fue el gran empresario de la fantasmagoría (I, 280), de la apariencia y de lo ficticio (II, 520-521), de una política abstracta, irreal (I, 290), como un continuo dar largas (X, 639). «Durante ella -escribe en Meditaciones del Quijote- llegó el corazón de España a dar el menor número de latidos por minuto» (I, 337). Al contrario que el periodo anterior, antes de 1860, que reivindica como la etapa más sana y fecunda que ha vivido España desde 1650, de la que sí se siente heredero: de su sentido moral de la vida (no de su República). Estos fueron profesores y escritores. Los de la Restauración: abogados y negociantes (III, 12), inmersos en la obsesión burguesa del utilitarismo que contesta, por ejemplo, Valle-Inclán, hermano mayor en la nueva familia espiritual, dice Ortega, con su literatura sin trascendencia, inútil, sin los personajes vulgares que fueron el hombre-medio de las novelas naturalistas (I, 25). Escribe el madrileño en «Vieja y nueva política», en 1914: «La Restauración significa la detención de la vida nacional» (I, 280): Lo que denuncia Azorín: el caballero de las violas para Ortega: porque busca lo humilde, lo olvidado, lo mínimo (II, 190). Con uno de los rasgos con el que coloca al 98 como antesala de la nueva sensibilidad: En su arte, que evita las expresiones excesivas, se produce una inversión de la perspectiva: lo pequeño ocupa el primer plano y lo monumental es sólo ornamento: «Como unas pinzas sujeta Azorín ese mínimo hecho humano, lo destaca en primer término sobre el fondo gigante de la vida y lo hace reverberar al sol» (II, 160). Es lo contrario a un filósofo de la historia. No hay en él nada solemne (II, 159). Maximus in minimis, escribe Ortega. Como una regresión al gusto primitivo, como la de algunos pintores contemporáneos a él (II, 191). Con el que reconoce una de las grandes aportaciones de los últimos años, dice en 1911: «Lo mejor que ha traído la literatura española en los últimos diez años ha sido los ensayos de salvación de los casinos triviales de los pueblos, de las viejas inútiles, de los provincianos anónimos, de los zaguanes, de las posadas, de los caminos polvorientos -que compuso [...] Azorín» (I, 200). Busca en cada cosa sólo sus costumbres, para sugerir la fuerza negativa de la repetición que es la vida, pues las innovaciones no son más que apariencia (II, 181). Sus personajes no tienen valor por sí mismos. Sino en la percepción de que cada uno de ellos es sólo uno más de una serie ilimitada compuesta de elementos idénticos (II, 177). Azorín piensa -por un poso, dice Ortega, de la creencia del siglo XIX- que son las criaturas anónimas, y no los grandes hombres, quienes dan forma a la vida social (II, 185-186). Sus libros son un mundo paralítico y moroso, porque son un ensayo de salvar el mundo. Al petrificarlo estéticamente, lo hace inmortal, porque el movimiento es para él la vida gastándose (II, 174). El pasado es su tema estético (I, 324). Pero no lo busca como el arqueólogo o el erudito; él quiere revivirlo: «revivir la sensibilidad básica del hombre a través de los tiempos» (II, 163-165). 
Lo llama poeta de lo castizo (un halago; nada que ver con escritor casticista) (II, 186): ha sido quien ha acertado con la brecha por donde la sensibilidad moderna puede penetrar en el recinto de la literatura vieja (I, 264). Ha hecho de lo castizo su materia; se ha sumergido en el pasado español, pero la obra de Azorín es actual: «Emplea los órganos sentimentales del ánima contemporánea para hacerla percibir, bajo la especie del presente, lo pasado» (II, 188). Así -señala Ortega en «Azorín: primores de lo vulgar»- ha visto el hecho radical de que España no vive actualmente, sino que la actualidad de España es la perduración del pasado: España no se transforma; se repite (II, 176). Escribe en «Nuevo libro de Azorín», en 1912: «El arte de Azorín consiste en suspender el movimiento de las cosas haciendo que la postura en que las sorprende se perpetúe indefinidamente como en un perenne eco sentimental. De este modo, se desvirtúa el poder corruptor del tiempo. Se trata, pues, de un artificio análogo al de la pintura. [...] Azorín reduce pasado y futuro a la sola dimensión del presente y en ella los hace cohabitar: dentro del presente yace el pasado en condensación y se halla el futuro preformado» (I, 240-241).

En los noventayochistas lo que busca Ortega en su arranque como filósofo es solo una nueva sensibilidad vital, que define en El tema de nuestro tiempo, de 1923, como la sensación radical ante la vida, el modo en que se siente la existencia en su integridad indiferenciada (III, 146-147). No su literatura, que olvida, o menosprecia, o la deja en un segundo plano, sólo como el soporte necesario (en muchos casos, piensa, de manera poco eficiente) para trasmitir esos primeros síntomas de cambio. El precursor es Baroja (II, 72). Al que Ortega tiene como referente fundamental en sus primeros artículos para otear los primeros pasos de esa nueva sensibilidad en Europa, que se distancia del utilitarismo de sus predecesores. A pesar de las limitaciones que le encuentra como novelista: «La corrección gramatical -dado que exista una corrección gramatical- abunda hoy en nuestros escritores. Sensibilidad trascendente, en cambio, se encuentra en muy pocos. Tal vez en ninguno como en Baroja», escribe (II, 75). Valora su sensibilidad, no sus libros (II, 93), que son, dice, un balbuceo (IX, 479-481). Baroja emplea, como en su propia vida, un procedimiento excesivamente impresionista: no se presenta el objeto al lector, sino la reacción subjetiva ante él. Y en la novela, asegura el madrileño, eso es fatal (II, 94). No consigue adentrar al lector en la realidad inventada. Sus libros son tan porosos que no afectan al lector: son libros sin cámara, sin interior, donde los personajes no ejecutan ningún acto. Más que una novela, dice muy gráfico, parece el pellejo de una novela (II, 96-98). Escribe en «Una primera vista sobre Baroja» (1910): «Esa preferencia por vocablos antiestéticos [...] es claramente incompatible con una poderosa voluntad de hacer arte» (II, 105). Su virtud más positiva es su falta de retórica: «Sinceridad, lealtad consigo mismo, asco hacia la ficción y el artificio -son eje y motor de su alma, de su arte y de su vida» (II, 101). El interés de Baroja es filosófico, no literario (II, 116). Como un metafísico holgazán, un metafísico sin metafísica (IX, 484). Tiene la cabeza llena de teorías -«más que un hombre, es una encrucijada» (I, 325)- pero no las dotes de teorizador (V, 563). Pero su Andrés Hurtado es él mismo y los escritores que comenzaron a publicar en 1898: el representante de una generación con la que se inicia una nueva etapa también en España (IX, 491). Su literatura es una protesta, un rechazo a las ideas y valores insuficientes de su cultura, al modo de pensar general, a la hipocresía de su régimen moral (II, 88). 
Un tratado completo de la indignidad del hombre (II, 113). Desde su ansia de sinceridad y lealtad consigo mismo; en la ausencia de un yo convencional con que cubrir su fondo insobornable (II, 84). Con los protagonistas que elige como héroes: vagabundos, que reúnen las dos tendencias que a él le interesan: la crítica y el momento dinámico (II, 73). Porque casi todas las cosas le parecen una farsa y casi todos los hombres unos farsantes (II, 84); y, las ideas de su época, insinceramente vividas (II, 83). En la atmósfera inmóvil de España, defiende el escritor vasco, la felicidad está en la acción. Por lo que sus personajes están fuera de la sociedad, en una región donde sólo existen las fuerzas biológicas puras que, vertiginosas, enfurecidas, van y vienen azotando al mundo (II, 113): aún no han sido pervertidos por una valoración utilista. Escribe en «Ideas sobre Pío Baroja»: «En El árbol de la ciencia dice Baroja del protagonista, Andrés Hurtado, estas palabras: 'La vida en general y, sobre todo, la suya, le parecía una cosa fea, turbia, dolorosa e indominable'. Esta impresión última y decisiva ante el conjunto del universo y de la existencia late, gime, trema so la primera página que Baroja escribió lo mismo que so la más reciente. De esa emoción, como de una amarga simiente, ha crecido la abundante literatura de este hombre, selva bronca y agria, áspera y convulsa, llena de angustia y desamparo, donde habita una especie de Robinson peludo, frenético y humorista, que azota sin piedad a los transeúntes» (II, 79).

Con el final del libro, con la muerte del protagonista, tras perder a su hijo y a su mujer en el parto, Baroja da de nuevo la vuelta al argumento, y acaba con la posibilidad que había abierto un poco antes de una vida nueva para Andrés Hurtado: Se suicida. Lo encuentran muerto su tío y un médico que atendió antes el parto, para cerrar las conclusiones de la novela: -Este muchacho no tenía fuerzas para vivir [...] -murmura Iturroiz. -Pero había en él algo de precursor- murmura el otro médico (Baroja, 1995: 303): Las dos claves con las que da Ortega en su análisis teórico del 98: una sensibilidad negativa para abrir una nueva sensibilidad.

\section{BIBLIOGRAFÍA}

Abellan, José Luis (1995): El filósofo «Antonio Machado». Valencia: Pre-textos.

Baroja, Pío (1995): El árbol de la ciencia. Madrid: Espasa-Calpe.

Calvo, José Luis (1998): La cara oculta del 98. Místicos e intelectuales en la España del fin de siglo (1895-1902). Madrid: Cátedra.

Machado, Antonio (1984): Juan de Mairena. Madrid: Espasa-Calpe.

Mainer, José Carlos (1986): La edad de plata (1902-1939). Madrid: Cátedra.

Marichal, Juan (1990): El intelectual y la política. Madrid: CSIC.

Molinuevo, José Luis (2002): Para leer a Ortega. Madrid: Alianza Editorial.

Ortega y Gasset, José (1983): Obras completas. Madrid: Espasa-Calpe.

Rodríguez Huéscar, Antonio (1994): Semblanza de Ortega. Barcelona: Anthropos. 


\section{ORTEGOVO RAZUMEVANJE POJAVA 98: \\ OS OBČUTLJIVOSTI V TIPANJU GENERACIJ}

Ključne besede: vitalni razum, življenjska občutljivost, generacija 98, negativna občutljivost, Andrés Hurtado

Ko Ortega y Gasset piše o umetnosti - in tudi o književnosti, želi seči dlje od umetnostne analize v ožjem pomenu besede. Običajno se ne spušča v podrobna vprašanja, svoj razmislek oblikuje v simptom, ki deluje kot vezni člen za eno od njegovih ključnih filozofskih vprašanj.

V zapisih o pisateljih skupine 98 opozori na zaznavanje nove občutljivosti, v skladu s katero prilagodi svojo filozofsko misel tako, da vpelje pojem »vitalni razum«, ki jemlje življenje kot dramo in ki ga vsaka generacija nanovo interpretira. Pripadniki skupine 98 kot vidna referenca te generacije, s katero se konča stoletje, delujejo kot os med dvema občutljivostma: tisto, ki se izčrpa z 19. stoletjem, in tisto, ki jo Ortega zasluti na začetku 20. stoletja. Vendar ti avtorji zgolj zrušijo tisto, kar je bilo prej: to je prvi korak, da ustvarijo novo Španijo od temeljev naprej. So začetek poti k novi občutljivosti, ne pa ta nova občutljivost: Baroja konča Drevo spoznanja s samomorom Andrésa Hurtada, ko ta med ženinim porodom izgubi njo in otroka. Hurtado sicer sluti neko novo življenje, vendar Baroja izključi to možnost, še preden jo dodobra ponazori. 